\title{
An Investigation of Environmental, Social and Governance Measures of Listed Mining Sector Companies in Australia
}

\author{
Kumudini Heenetigala, Chitra De Silva Lokuwaduge \\ Anona Armstrong and Amali Ediriweera \\ Victoria University, Australia
}

\begin{abstract}
The aim of this paper is to determine the extent of ESG reporting and to determine the nature and type of ESG indicators used to report ESG disclosures of listed mining sector companies in Australia. The study was conducted with secondary data collected from integrated or sustainability reports of Top 100 Companies in the Diversified Metal and Mining Sector for the year 2013. A pilot study was conducted with 12 companies which were top end of market capitalisation and compared with total of 30 companies. Findings revealed that majority of the companies had a sustainability report and the trend is towards integrated reporting and majority of the companies at the top end of market capitalisation reported on non-financial disclosures. However, the measures used for environmental and social indicators is an issue because the same indicator was measured differently by companies even in the same industry, whereas, indicators used for governance was of regulatory nature and was comparable. This study showed that there is a clear need for uniform measures to report ESG indicator.
\end{abstract}

Key Word

Environment Social and Governance, Non-financial reporting, ESG measures, GRI Guidelines, Mining Companies

\section{Introduction}

Environmental Social and Governance (ESG) reporting is not a new phenomenon. Even though, ESG has been around for some time, attention to these issues was highlighted as a result of the Global Financial crisis (GFC) (Galbreath 2013). The International Corporate Governance Network (ICGN), United Nations Environmental Program Finance Initiatives (UNEP FI), United Nations Principles of Responsible Investment (UN PRI) and Carbon Disclosure Project (CDP) are some of the international organisations seeking improvement in various types of ESG disclosures and are signatories to initiatives to enhanced ESG disclosures (Chartered Accountants of Canada 2010).

Expectations by investors for corporate disclosures beyond what is disclosed in financial reporting has also driven much attention to disclosures of ESG information by corporates, especially the institutional investors tend to look at longer investment horizons (Chartered Accountants of Canada

Copyright (C) 2015 Victoria University. This document has been published as part of the Journal of Law and Governance in both online and print formats. Educational and non-profit institutions are granted a non-exclusive licence to utilise this document in whole or in part for personal or classroom use without fee, provided that correct attribution and citation are made and this copyright statement is reproduced. Any other usage is prohibited without the express permission of the publisher. 2010). Furthermore, advisors such as Goldman Sachs, factor ESG information in their investment decisions. They believe that "the indicators they use to assess performance with respect to Environmental, Social and Corporate Governance issues are essential to analyse a company's ability to sustain competitive advantage over the long term"(Goldman Sachs 2008). 
In the past it was beyond the fiduciary responsibility to consider ESG factors in investment decisions by trustees. However, as a result of legal interpretations on the principle of fiduciary responsibility of investment trustees, today it may not be considered a breach of fiduciary responsibility not to consider ESG matters in their investment decisions by the trustees (UNEPF Asset Management Working Group 2009).

According to the study conducted by Chartered Accountant of Canada (2010) interviewees indicated that they use range of ESG information. Governance was the most standardized and available category, environmental disclosures were mainly due to pressure from regulators and market participants as a result of climate change and are becoming more available and standardized and social information was the least standardized category especially in related to provision of relevant metrics. However, disclosure of non-financial information can be complex sometimes hard to understand and implement. A key feature of non-financial information is that, it can be specific to the operation of each particular company which can result in disclosures varying from company to company. Hence, representation could be inconsistent across companies. Apart from the above company's may use different definitions and labels to disclose non-financial information that may not be quantifiable or monetized which hamper comparability (Yen 2004). Therefore, aim of this paper is to determine the extent of ESG reporting and the nature and type of ESG indicators used to report ESG disclosures.

\section{What is Environmental Social and Governance?}

The concept of ESG is described using different terminology in various context such as risk valuation, socially responsible investment and corporate socially responsibility (Galbreath 2013). It is a key indicator of risk management, management competence and non-financial performance (Galbreath cited in Lundstrom and Svensson 2014). Lundstrom and Svensson (2014) states environmental, social and governance refers to three broad dimensions of corporate behaviour. Capital markets use Environmental, social and governance as a generic term to evaluate corporate behaviour and to determine the future financial performance of companies (Financial Times 2014). Accordingly, "ESG factors are the performance metrics used to evaluate a company's performance in different dimensions". These factors are used to evaluate the sustainability and ethical impact of a corporation (Lundstrom and Svensson 2014). Financial Times (2014) reports ESG factors as a subset of nonfinancial performance indicators which include sustainable, ethical and corporate governance issues such as managing the company's carbon footprint and ensuring there are systems in place to ensure accountability. ESG covers many issues related to environment (Carbon emissions, water use and pollution, climate change and energy), social responsibility (human rights, gender equality, health and safety, fair trade principles, product safety, minorities) and corporate governance (board independence, corruption and bribery, reporting and disclosure, shareholder protection) (Galbreath 2013).

According to UNEP FI and Mercer (2007) the term ESG "emerged globally to describe the environmental, Social and corporate governance issues that investors are considering in the context of corporate behaviour. They states that there is no definitive list of ESG issues exists, but they typically display one or more of the following characteristics:

- Issues that have traditionally been considered non-financial or not material

- A medium or long-term time horizon

- Qualitative objects that are not readily quantifiable in monetary terms

- Externalities (costs borne by other firms or by society at large) not well captured by market mechanisms

- A changing regulatory or policy framework

- Patterns arising throughout a company's supply chain (and therefore susceptible to unknown risks)

- A public-concern focus 


\section{Why are ESG indicators important?}

ESG is considered important to the investment community, because ESG issues are seen as financially material to an investment portfolio (O'Dwyer, Owen et al. 2011). Yen (2004) states that information provided by accounting and financial reporting data shows a declining ability to report information that is useful in assessing firm value and management performance. Intangible assets accounts for significant proportion of a value of a company and are becoming important in the current business environment, especially due to the long-term perspective taken by investors (Bassen and Kovacs 2008), but traditional accounting methods fail to capture their value (Kossovsky, cited in Bassen and Kovacs 2008).

Another important consideration for the importance of ESG indicators are that according to the efficient market theory, all known information is reflected in share prices and new information also has the potential to impact the value of shares. Even though extra-financial information may not affect the price during the normal operation of the business, in case of existence of reputational or monetarily quantifiable litigation risks, investment professionals tend to turn their attention to information that can have an impact. As a result, companies tend to make an effort to provide disclosures of extra-financial information that are not captured in the financial data through the corporate social responsibility, environmental, sustainability and corporate governance reports (Bassen and Kovacs 2008).

The Chartered Accountant of Canada (2010) states, according to the view of British Columbia Investment Corporation, ESG issues directly impact long-term investment returns. A similar view was reported by companies and financial institutions participated at a workshop that was conducted by UNEP FI and WBCSD. The participants in the workshops argued that "ESG factors can have longterm consequences on a company's financial performance, either for better or for worse. They considered that ESG factors are at the core of business. However, the depth and breadth of ESG factors are not fully valued by investors and company management. Companies believe that mainstream asset managers currently under or overvalue the long-term intrinsic value of companies because they fail to routinely integrate ESG factors into their investment analysis and decisionmaking" (UNEP FI and WBCSD 2010).

\section{Motivation for ESG Disclosures}

Deegan (2002) refers to motivation for undertaking voluntarily reporting on social and environmental activities as desire to comply with legal requirements, "economic rationality" consideration, a belief in an accountability or responsibility report, desire to comply with borrowing requirements, to comply with community expectations, as a result of certain threats to the organisation's legitimacy, to manage particular stakeholder groups, to attract investment funds, to comply with industry requirements or particular codes of conduct, to forestall efforts to introduce more onerous disclosure regulations and to win particular reporting awards. He states that it may be unrealistic to state that one motivation dominates the others, but many of these motivations may be interrelated.

Furthermore, a study conducted by Chartered Accountants of Canada (2010) reported on five main reasons for use of ESG information by investors. They were to inform risk and return potential, evaluate management quality, engage with companies and inform proxy voting, develop customised investment products or portfolios and assess asset managers. This study agreed with the February 2009 issue of The McKinsey Quarterly which states 80\% of CFO's (more Europeans than North Americans) believe that ESG information serves as a proxy for the quality of a company's management. Accordingly, Corporate Knights (2010) reports, Goldman Sachs looks for managements' responses to ESG performance in five broad categories when assessing quality of 
management. These are corporate governance, leadership, employee recruitment and retention, stakeholder relationships and environmental management.

\section{Theories of ESG}

There are many theories that explain company's motivation to disclose ESG information (Jenkins HM 2004). They relate to regulation and standards, legitimacy and stakeholders. Therefore, in this study we draw the attention to social contract theory, legitimacy theory and stakeholder theory.

\section{Social Contract Theory}

Social contract theory sees society as a series of contracts between members of society and society itself (Gray, Owen \& Adams 1996). There is a school of thought which sees social responsibility as a contractual obligation the firm owes to society (Donaldson 1983). If the society is not satisfied with the way the organisation operates, the society will revoke the contract with the organisation. This might be evidenced through reduction or eliminating consumer demand, suppliers of factors eliminating the supply of labour or financial capital to the business, lobbying for increased taxes, fines or laws to prohibit those actions that do not conform with the expectations of the community (Deegan 2002).

\section{Legitimacy Theory}

Legitimacy theory is based upon the notion that there is a social contract between the society and an organisation. A firm receives permission to operate from the society and is ultimately accountable to the society for how it operates and what it does, because society provides corporations the authority to own and use natural resources and to hire employees (Deegan 2004). If society feels that an organisation has breached its side of the social contract, then the survival of the organisation will be threatened. Thus legitimacy is considered to be a resource which an organisation is dependent upon for survival (Dowling and Pfeffer 1975). Proponents of legitimacy theory refers to the society and compliance (Gray, Kouhy et al. 1995).

Matthews (1993) defines legitimacy theory as follows: "Organisations seek to establish congruence between the social values associated with or implied by their activities and the norms of acceptable behaviour in the larger social system in which they are a part. In so far as these two value systems are congruent we can speak of organisational legitimacy. When an actual or potential disparity exists between the two value systems there will exist a threat to organisational legitimacy". Accordingly, Lindblom (1994) states that an organisation has legitimacy, when "an entity's value system is congruent with the value system of the larger social system of which the entity is a part". If society feels that an entity has breached its side of the social contract, then the entity's legitimacy is under threat. Events such as the Alaskan oil spill in Valdez in 1989, for example, may have a detrimental impact on society's perception of both an organisation and the industry to which it belongs (Patten 1992).

The legitimacy theory emphasizes that an organization must consider the rights of the public at large, not merely the rights of the investors. Failure to comply with societal expectations may result in sanctions being imposed in the form of restrictions on firms operations, resources and demand for its products. Social and environmental researchers particularly tend to utilize legitimacy theory, to explain why corporate management undertake certain actions such as disclosing particular items of social and environmental information. It does not provide prescription about what management ought or should do and is a positive theory which seeks to explain or predict particular managerial activities (Deegan 2014).

Much empirical research has used legitimacy theory to study social and environmental reporting, and proposes a relationship between corporate disclosures and community expectations (Deegan 2004) and according to Tilling (2004) legitimacy theory provides a powerful mechanism for understanding 
voluntary social and environmental disclosures made by corporations. According to Deegan (2002) due to the desire to legitimise an organisations operations, legitimacy theory has been used as the theoretical basis for the environmental social disclosures. Furthermore, Lindblom (1994) and Patten (2005) has also suggested practice of environmental disclosures as a tool of legitimisation. Therefore, in relation to legitimacy theory, a strategy used for legitimacy is disclosure.

\section{Stakeholder theory}

ESG disclosures made by the companies are regarded as issues important to a wide range of stakeholders. They cover issues that are more than economic concern and also can impact economic concerns (Gray, Kouhy et al. 1995; Jenkins HM 2004). Therefore, a theory that provides similar insights to legitimacy theory is stakeholder theory. A stakeholder is any group of individuals who can affect or is affected by the activities of the firm, in achieving the objectives of the firm (Freeman 1984). Apart from the shareholders, a company has responsibility to suppliers, customers, employees, the government and the community, which means under the social responsibility model they must be accountable to the other stakeholders (Thorne, Ferrell et al. 2011). Accordingly, Shareholder wealth maximization way of thinking is changing to stakeholder wealth maximization, where company value management system is based not only on economic profit maximization, but also on ESG maximization. ESG maximization can be reached only if stakeholder engagement process is implemented in the management system of the company (Martirosyan and Vashakmadze 2013).

The Study by John Evans and Peiris (2010) reported, a significant positive relationship between broader ESG factors and firm valuations indicating that higher rated companies are associated with higher earnings multiples, suggesting that ESG factors impact corporate financial performance, therefore, relevant for consideration of investment decision-makers. This shows that in order to be successful, companies not only have to be responsible to shareholders, but also rely on management of a variety of stakeholders who have a stake in the social and financial performance of the firm (Donaldson and Preston 1995).

Gray, Owen et al. (1996) states that "the more important the stakeholder to the organization, the more effort will be exerted in managing the relationship. Information is a major element that can be employed by the organization to manage (or manipulate) the stakeholder in order to gain their support and approval, or to distract their opposition and disapproval". Accordingly, manager's will have an incentive to disclose information on various programs and initiatives to those stakeholders who have a particular interest in the organisation to indicate that they are conforming to stakeholder expectations (Deegan 2002).

However, Gray, Kouhy et al. (1995) states that it is incorrect to treat legitimacy theory and stakeholder theory as two distinct theories. They argue that there is an overlap between legitimacy theory and stakeholder theory.

\section{What are the ESG Issues}

Importance of ESG has brought the attention of academics, analysts and regulators to define areas that are topical for reporting of ESG. As a result, they have identified issues related to ESG that are important to companies and investors in their decision-making. European Federation of Financial Analysts Societies (2009) identified nine topical areas of ESG issues that apply to all sectors and industries which are energy efficiency; greenhouse gas (GHG) emissions; staff turnover; training \& qualification; maturity of workforce; absenteeism rate; litigation risks; corruption and revenues from new products. Global Reporting Initiative (GRI) guidelines require companies to report on specific standard disclosures which are economic, environmental and social. Social category is further divided into four sub categories which are labour practices and decent work, human rights, society and product responsibility (Global Reporting Initiative 2013). 
Furthermore, a study conducted by Chartered Accountants of Canada (2010) identified number of issues related to oil and gas industry. Environmental issues were related to climate change, renewable energy, water, pollutant releases, biodiversity, site remediation and decommissioning, land use, chemical regulations, resource use and efficiency, vehicle fuels and engine technologies and market for environmental services. Social issues included labour, stakeholder relations, operations in emerging markets, pipeline safety, energy security, anti-corruption, human rights.

Bonime-Blanc (2014) provides a snapshot of ESG issues in Table 1. She considers a more inclusive view for governance and includes legal and regulatory issues.

Table 1: Environmental, Social and Governance Issues

\begin{tabular}{|l|l|l|}
\hline \multicolumn{3}{|l|}{ Sampling of environmental, social and governance (ESG) issues } \\
\hline $\begin{array}{l}\text { Environmental } \\
\text { Climate Change issues } \\
\text { Sustainability } \\
\text { Environmental laws \& } \\
\text { regulations } \\
\text { Toxic waste laws \& } \\
\text { regulations }\end{array}$ & $\begin{array}{l}\text { Suman rights } \\
\text { Labour rights } \\
\text { Child labour }\end{array}$ & $\begin{array}{l}\text { Governance } \\
\text { Anti-corruption } \\
\text { Anti-money laundering } \\
\text { Anti-fraud }\end{array}$ \\
& Health \& safety \\
Riscrimination, Harassment & Conflict of interest \\
\hline Andrea Bonime-Blanc 2014 & \&ullying & Corporate governance \\
\hline
\end{tabular}

\section{Benefits of ESG disclosures:}

ESG create value for companies through increase in sales, decrease in costs or reduced risks as well as ESG programs that are best, creates financial values for a company in ways the market already assesses them (Bonini, Koller et al. 2009). According to Owen (2007) "there is a strong business case to implement sustainable management practices in relation to environmental social and governance issues", because firms can do well while doing good, which means that sustainability can increase profits and present opportunities for value creation and have an impact on company's revenue. According to case studies conducted by Bonini, Koller et al. (2009) environmental, Social and governance programs can also support growth, improve returns on capital, reduce risk or improve quality of management.

According to McKinsey Global Survey Results" the most widely known way that environmental, social and governance programs create value is by enhancing the reputation of companies and their stakeholders' attitudes about their tangible actions" (Bonini, Koller et al. 2009). They also state that, financial valuable objectives such as better regulatory settlements, price premiums, increased sales, reduced risk of boycott and higher retention of talents partly depends on the reputation of the company for ESG programs that meet the needs of the community and those that go beyond regulatory requirements and industry norms.

\section{Issues related to ESG disclosures}

The study conducted by Chartered Accountants of Canada (2010) reported various issues related to ESG disclosures. They reported that companies used various different units to report ESG 
performance and also provided ESG data in the form of ratios, charts or other graphical forms, instead of using absolute numeric values. Another important issue was the lack of standardized, comparable, sector based metrics that are updated regularly. Even though GRI's sustainability reporting guidelines and accompanying protocols have helped in standardization of ESG reporting, companies tend to report GRI compliance in different degrees. To be comparable ESG information needs to be transformed into consistent units. Ability to obtain data is important, because asset managers and ESG research providers can only assess the companies that have the ability to obtain data. Companies that have adopted ESG disclosures and management practices, benefit from access to larger and growing pool of investment capital.Timeliness is an issue for integration of ESG information with financial and operational data for investors. Some companies do not publish the sustainability report at the same time as annual reports and some may publish every two years.

Apart from the above, an issue that is considered crucial when disclosing ESG information is materiality (Chartered Accountants of Canada 2010). Materiality of ESG issues can differ substantially between industries. For example resource intensive industries such as mining have a different exposure to environmental, social and governance factors than for the commercial real-estate sector (Owen 2007). Accordingly, GRI worked with a number of stakeholders to identify the most material ESG issues in different sectors, which resulted in G4 Sustainability Reporting Guidelines (Global Reporting Initiative 2013). However, where companies and investors are able to agree on a materiality of a ESG factor, the management of that factor is often not explained by companies in comparable terms, for example, an explanation of why an issue is more material now than before or how one company manages ESG factors better than its competitors and the use of comparative language (UNEP FI and WBCSD 2010).

Another important issue is the measurement. Unlike financial data, there are no generally accepted measures for ESG data. Studies report differing measures used to report ESG information (Vintro and Comajuncosa 2010).

\section{ESG Measurement}

Peter Drucker once said "What you can't measure, you cannot manage. What you can't manage, you cannot change." (Blanc, Cozic et al. 2013). Unless you are able to measure you do not know if something is getting better or worse. You do not know if you are successful unless it is defined and tracked.

Bonini, Koller et al. (2009) states that even though executives and investors believe that the impact of ESG programs are long-term and indirect, therefore measurement is impossible, their research suggest otherwise. They states that impact of environmental programs can be measured in the short-term using traditional business metrics such as cost efficiency.

The study conducted by Chartered Accountants of Canada (2010) reported on the performance indicators used by the companies. They used relevant performance indicators and measures for each issue and in some cases they used their own industry wide performance indicators and measures. An example of performance indicators used for labour and employee relations were percentage of employee turnover, percentage of workforce unionized, the ratio of lowest wage to minimum wage and ratio of jobs offered to jobs accepted. Interviewees also stated that assessments are usually made on a sector by sector basis in order to identify the best and worst class of companies. A study conducted by Bonini, Koller et al. (2009) reported the impact of Environmental, Social and Governance work using social responsibility dash-board. The dash-board includes metrics for workplace engagement, ethics and integrity; supplier diversity; environmental impact; employeecommunity involvement; stakeholders' perspective on social responsibility; and community giving. These metrics track the company's progress in meeting its social mission and helping people live a healthier living. The dash-board is used by the board and the senior executives to measure the performance and as a guide for discussions on future priorities, programs, resources and results. 
Bonini, Koller et al. (2009) also state that progress has been made by companies in relation to tracking operational metrics such as tons of carbon emitted, or social indicators for example number of students enrolled in a program. However, it is difficult to link the metrics and indicators to real financial impact. They also state that there are "others who also insist the effect of such programs are either too direct to value or too deeply embedded in the core business to be measured meaningfully".

Daniel (2012) reported on a case study conducted with Interserve, they held workshops to understand what data are practical to collect. Key questions were on how to address quantifiable and qualitative information including whether to score, monetise or explain information so that meaningful insight accompanies the figures. They also stated that some are not collected in a structured way across business, while other data are more reliable. Furthermore, Spiers from interserve reported "We want to use measurement as a helpful decision-making tool but not as the be all and end all what we do. It's just a way of looking at things. Measurement and data are certainly important but not the reason we are doing this".

Hřebíček, Soukopová et al. (2011) also state that to be comparable across all companies and also useful for mainstream investment analysis, ESG data needs to be transformed into consistent units and is presented in a balanced and a coherent manner for ESG indicators.

\section{Different ESG Guidelines}

Currently, there are no uniform criteria that could be applied to measure ESG indicators. This is addressed by various organisations. Dow Jones Sustainability Index, KLD-Nasdaq Social Index, Domino 400 Social Index, FTSE4Good Index and Global Reporting Initiative (GRI) are some of the bodies that have proposed various measures for CSR indicators. The indicators developed by these organisations were commonly used as reference for Stock Market investments (Vintro and Comajuncosa 2010). However, widely used framework for sustainability reporting is the framework developed by GRI. It is a framework that can be applied to organisations in all sectors, sizes and regions (Hřebíček, Soukopová et al. 2011). GRI also has developed specific standard disclosures for Mining and Metal sector. In March 2011, they released a more updated version G3.1. The framework included Reporting Guidelines and sets out the principles and indicators that could measure and report on economic, environmental and social performance (Global Reporting Initiative 2013). Even though GRI has been a useful tool in improving the standardisation of reporting in many sectors, compliance with G3.1 differs between companies as well as due to use of different interpretations of the tools applied for standards for their reporting (Hřebíček, Soukopová et al. 2011). In 2013, the updated version of GRI guidelines G4 Sustainability Reporting Guidelines and G4 Sector Disclosures for mining and metal sector companies wishing to use as guidelines was launched (Global Reporting Initiative 2013).

\section{Mining Sector in Australia}

Mining sector contribution to Australian economy is relatively high. Mining boom has had a significant impact on the living standards of Australians. Mining industry contributes to nearly $6 \%$ of Australia's GDP and more than $35 \%$ of receipts from export. It's contribution to national employment was about $1.3 \%$ and $20 \%$ of market capitalisation was contributed to mining comprising of nearly one-third were listed companies (Galbreath 2013). However, the negative impacts of mining operations have brought the attention of institutional investors to focus on ESG issues.

Mining industry is associated with many challenges related to economic, environmental and social issues. Even though it has economic benefits related to employment and wealth creation, on the other hand it has variety of environmental impacts, including depletion of non-renewable resources, disturbance of the landscape and above-average threats for health and safety of workers and citizens (Azapagic 2004). Depletion of mining resources as a result of mining is a major concern for sustainability development. Mining is regarded as one of the most environmentally and socially 
disruptive activities undertaken by business. According to Warhurst A. (2001) incidents related to environmental disasters \& human rights are related to mining or petroleum industries. Maintaining a licence to operate is a constant challenge for mining sector companies. For example resistance by social organisations, impact on the agriculture, pollution, health impacts and lack of community engagement (Jenkins and Yakovleva 2006).

Furthermore, Jenkins HM (2004) reports that CSR in the mining industry is about balancing the diverse demands of communities and protecting the environment whilst making profit. Therefore, from the perspective of mining sector, CSR is about responding to the shareholders as well as stakeholders including employees, customers, affected communities and the general public on issues such as human rights, employee welfare and climate change (Hamann R. 2003). Azapagic (2004) has identified many different stakeholder related to mining sector as industry stakeholders, employees, trade unions, contractors, suppliers, customers, shareholders, creditors, insurers, local communities, local authorities, government and NGO's.

\section{Methodology}

\section{Sample and Data Collection}

As discussed above, companies in the mining sector has a strong impact on the environmental, social and governance issues, due to the nature of activities undertaken by business. Many environmental disasters or human rights incidents involving mining have contributed to debates about social and environmental responsibility (Jenkins and Yakovleva 2006). To investigate the extent of disclosure of non-financial information and the indicators used to measure non-financial information of mining companies in Australia, the sample was selected from Top 100 companies in the Diversified Metal and Mining sector companies listed on the Australian Securities Exchange (ASX). The pilot study was conducted with 12 top tier companies in the metal \& mining sector based on the market capitalization and the final study was conducted with 30 companies.

This study was conducted from secondary data collected from annual reports or sustainability reports for year 2013. Annual reports are considered to be more publicised and visible document and provide important social and environmental information and are produced more regularly by companies (Tilt 1994; Neu, Warsame et al. 1998).

\section{Results and Analysis}

This paper reports the results from the pilot study which was conducted with the top 12 companies and compares with the final sample of 30 companies. Results of the study reported the extent of ESG reporting by the mining companies in Australia and the measures used for indicators.

\section{Demographics}

First of all the demographics of the sample was examined for the pilot study and the final sample. Demographic of the pilot study reported majority (33.3\%) had their headquarters in Melbourne, $16 \%$ in Perth, $8.3 \%$ in NSW, Brisbane and Sydney and $25 \%$ had their headquarters outside Australia, where as the final sample showed majority $(46.7 \%)$ had their headquarters in Perth, $20 \%$ in Melbourne, $20 \%$ in NSW, Brisbane and Sydney and 13.3\% had their headquarters outside Australia.

Employees were compared for both samples. Majority (75\%) of the companies in the pilot study had less than 10,000 employees and one company had more than 50000 employees in the pilot study, whereas in the final sample also majority (53\%) of the companies had less than 10,000 employees, 4 reported between 10000 and 50000 and one company had more than 50000 employees. However, 9 companies did not report on the total number of employees. 
Pilot study reported 50\% (6) had less than 1000 US \$ million net sales and $16.7 \%$ (2) had more than

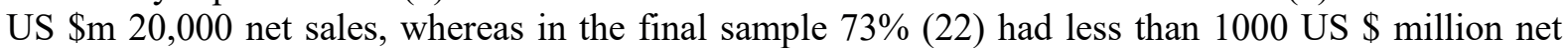
sales and 6.7\% (2) had more than US \$m 20,000 net sales.

\section{Reporting}

Investigation of the reporting practices of the pilot study showed $83.3 \%$ (10) had a separate sustainability report and $16.7 \%$ (2) had integrated reports. However, the final study showed that $43.3 \%$ (13) had a separate sustainability report and 40\% (12) had integrated reports. Sixteen Percent (5) did not have either.

Types of operations reported in the pilot study were extractive $91.7 \%$ (11) and recycling $8.3 \%$ (1). Final study showed that the types of operations reported were extractive $96.7 \%$ (29) and recycling $3.3 \%$ (1). Size of the operational site was reported by $50 \%$ of the companies in the pilot study and was two reported the size of the operational site in $\mathrm{Km}^{2}$ and four reported in Hectares, whereas $23.3 \%$ (7) the reported Size of the operational site in the final study and this was reported by three in $\mathrm{Km}^{2}$ and four reported in Hectares.

\section{Environmental indicators}

Environmental indicators refer to disclosures relating to the impact of businesses interaction with the natural environment, environmental protection as well as use of resources.

This study captured the use of renewable and non-renewable material. In the pilot study two companies $(16 \%)$ reported on renewable and three $(24.9 \%)$ on non-renewable material. Final Study reported three companies $(9.9 \%)$ on non-renewable and two (6.6) reported on renewable material. In both studies measures reported varied from Million tons, Kilo Tons to other and the value of the total material used were in either US\$ or AUD\$.

All (12) companies in the pilot study reported on fuel consumption for renewable and non-renewable sources. In the final study, fuel consumption for non-renewable sources was reported by $43.3 \%$ (13) and renewable sources was reported by $23.4 \%$ (7). The indicators used were Giga joules, Tera joules and Peta Joules by both studies. Total fuel consumption in the pilot study was $91.7 \%$ (11) whereas the final study reported $66.6 \%$ (20). Total fuel sold was reported in joules or MWh in both studies. They also reported on volume of water withdrawn. The pilot study reported surface water $58.3 \%$ (7), ground water $66.6 \%$ (8), rain water $16.7 \%$ (2), Municipal water supplies $33.3 \%$ (4), Sea water $41.7 \%$ (5) and recycled and reused water $58.3 \%$ (7). Total study reported surface water $(36.7 \%,(11))$, ground water $(33.3 \%(10)$, rain water $6.7 \%$ (2), Municipal water supplies $(16.6 \%(5)$, Sea water $(16.6 \%(5)$ and recycled and reused water $(26.7 \%$ (8). Measures used varied from kilo litres, Mega litres and Giga litres.

All companies except one in the pilot study reported on biodiversity value characterised by attribute of high biodiversity value areas outside protected areas. Pilot study reported $66.7 \%$ (8) on terrestrial, $8.3 \%$ (1) reported freshwater and $16.7 \%$ (2) reported both terrestrial and freshwater. Eighty percent (24) of the total sample reported on terrestrial, 3.3\% (1) reported on freshwater and $13.3 \%$ (4) reported both terrestrial and freshwater.

The number of total sites that were assessed under the criteria needing Biodiversity Management Plan in the pilot study was reported in numbers $33.3 \%$ (4) and Hectares $16.7 \%$ (2). The total sample reported the number of total sites that were assessed under the criteria needing Biodiversity Management Plan in numbers by $20 \%$ (6) and in Hectares by $7 \%$ (2).

According to the GRI guidelines (G4) reporting on GHG emissions is based on the reporting requirement of the World Resource Institute (WRI) and World Business Council for Sustainable 
Development (WBCSD) GHG Protocol Corporate Accounting and Reporting Standards (GHG Protocol). GHG Protocol classifies GHG emissions into Scope 1, Scope 2 and Scope 3. Scope 1, reports on direct GHG emissions and is related to operations that are owned and controlled by the organisation. All the companies in the pilot study reported on direct GHG emissions. However, 50\% (6) reported in Tonnes, 8.3\% (1) in Kilo Tonnes and 41.7\% (5) in Mega Tonnes. Whereas only 76\% of the companies in the total sample reported on direct GHG emissions and 53\% (16) reported in Tonnes, 3.3\% (1) in Kilo Tonnes and 20\% (6) in Mega Tonnes and 23\% (7) did not report.

Scope 2 reports on energy indirect GHG emissions resulting from the generation of Purchased or acquired electricity. Indirect GHG emissions were reported by $75 \%$ (9) of companies in the pilot study and $41.7 \%$ (9) reported in Tonnes and 33.3\% (4) reported in Mega tonnes. In the total sample, indirect GHG emissions were reported by $66.7 \%$ (20) companies. Fifty percent (15) reported in Tonnes and 16.7 (5) reported in Mega tonnes.

None of the companies in the pilot study reported on Scope 3, emissions that are indirect and occurs outside the organization including both upstream and down-stream emissions, whereas, $16.7 \%$ (5) of the companies in the total sample have reported on Scope 3 emissions. GHG emission reductions achieved as a direct result of initiatives to reduce emissions were reported as a quantity or as percentage by $83.7 \%$ (10) of companies in the pilot study whereas only $36.7 \%$ (11) reported in the total sample in quantity or as percentage.

Four companies (33.3\%) from the pilot study reported on Ozon depleting substances, one $(8.3 \%)$ reported in Kilo Grams and three (25\%) reported in Tonnes and $13.3 \%$ (4) of companies in the final sample reported on Ozon depleting substances. One (3.3\%) reported in Kilo Grams and three (10\%) reported in Tonnes.

Total volume of planned and unplanned water discharges were reported by seven $(58.3 \%)$ companies in the pilot study and one (8.3\%) reported in Kilo litres, five $(41.7 \%)$ in mega litres and one $(8.3 \%)$ in Gigs litres. Whereas total volume of planned and unplanned water discharges were reported by eight (26.6\%) companies in the total sample and one (3.3\%) reported in Kilo litres, six (20\%) in mega litres and one $(3.3 \%)$ in Giga litres.

Total weight of hazardous non-hazardous waste was reported by $75 \%$ of companies in the pilot study in tonnes, kilo tonnes, million tonnes and tonnes and litres. Whereas only $36.7 \%$ of the companies in the total sample reported on hazardous non-hazardous waste also in tonnes, kilo tonnes, million tonnes and tonnes and litres.

Only two (16.7\%) companies in the Pilot study reported on spills and it was in litres. Final study reported three $(10 \%)$ and all reported in litres.

\section{Social Indicators}

Social indicators focus on wider responsibilities of business to the communities in which it operates, employees and to society in general (Azapagic and Perdan 2000). Social issues reported by companies were mainly on employees, human rights, health \& safety, gender and employment of indigenous people.

Sixty seven percent (8) of the companies pilot study reported on total number of employees either as a percentage $16.7 \%$ (2) or a number $25 \%$ (3) or both $25 \%$ (3). Thirty three percent (4) reported by Gender, Eight percent (1) reported by Gender \& age, eight percent (1) reported by Gender \& region, eight percent (1) reported by Gender region \& product and eight percent (1) reported by age, region \& product. Sixty seven percent (20) of companies in the total sample also reported on total number of employees either as a percentage $(43.3 \%)$ or a number $(13.3 \%)$ or both $(10 \%)$. They also reported by 
gender (53.3\%), Gender \& age (3.3\%), Gender \& region (3.3\%), Gender region \& product $(3.3 \%)$ and age, region \& product $(3.3 \%)$.

Employee turnover was reported by $24.9 \%$ of the companies by region $(8.3 \%)$, gender $\&$ age $(8.3 \%)$ and gender, age \& region $(8.3 \%)$ in the pilot study, whereas employee turnover was only reported by $9.9 \%$ (3) one by region (3.3\%), one by gender \& age (3.3\%) and one by gender, age \& region $(3.3 \%)$. It was reported as a percentage and or as a number.

Health and Safety was reported in lost days, injury rate. Eighty three percent (10) of companies in the pilot study that reported on lost days and injury rate used million hrs (41.7\%), total hrs (16.7\%), per $200,000 \mathrm{hrs}(16.7 \%)$ and other $(8.3 \%)$. In the total sample sixty Percent (21) of the companies reported on lost days and Fifty percent (15) of the companies reported on injury rate used million hrs, total hrs, per 200,000hrs and other.

Five (41.7\%) companies reported on fatalities in the pilot study and five (16.6\%) companies reported on fatalities in the total sample.

Training provided to employees in the pilot study was reported by $16.6 \%$ (2) of companies, whereas in the total sample $13.3 \%$ (4).Training on human rights policies were reported by $33.3 \%$ (4) of companies in the pilot study and $13.3 \%$ (4) of the companies reported in the total sample. In both samples, one reported the number of hours used for training and three reported as per employees.

Employment of indigenous people were reported by five (41.7\%) of the companies in the pilot study. Two (16.7\%) reported as a percentage, two (16.7\%) reported as per numbers and one $(8.3 \%)$ reported in both. Employment of indigenous people in the total sample was reported by six $(20 \%)$ of the companies in the pilot study. Three $(10 \%)$ reported as a percentage, two $(6.7 \%)$ reported as per numbers and one $(3.3 \%)$ reported in both.

Number of operations with implemented local community engagement was reported by $58.3 \%$ (7) of companies in the pilot study, whereas only $33.3 \%$ (10) was reported in the total sample.

\section{Governance indicators}

Corporate governance in Australia is based on a more flexible approach which is a principle-based framework. The recommendations are not mandatory and is not intended to provide a reference point for companies about their corporate governance structures and practices. If a listed company considers that a recommendation is inappropriate to its particular circumstances, it has the flexibility not to adopt it - a flexibility tempered by the requirement to explain why - the "if not, why not" approach.

This study also investigated the governance practices of the sample of 30 companies, which is reported in the table 1 . All the 30 companies reported on the structure of the boards relating to number of executive directors, non-executives, independent directors, board committees, females in the board. Tenure of the board was reported by 11 companies in the pilot study and 28 in the final sample. Number of committees responsible for decision-making on economic, environmental and social impacts was reported by all the companies in the pilot study and 28 companies reported in the final sample All the companies in the pilot study reported on the frequency of the director board's review of economic, environmental and social impacts, risks and opportunities, whereas 96.7\% (29) reported in the final sample.

Table 1: Governance practices

\begin{tabular}{|l|c|c|}
\hline Governance Indicator & $\begin{array}{c}\text { Pilot study } \\
\text { (12) }\end{array}$ & $\begin{array}{c}\text { Final Sample } \\
\text { (30) }\end{array}$ \\
\hline Board Structure & 12 & 30 \\
\hline No of Executive Directors & 12 & 30 \\
\hline
\end{tabular}




\begin{tabular}{|l|c|c|}
\hline No of Non-executive Directors & 12 & 30 \\
\hline No of Independent Directors & 12 & 30 \\
\hline No of Board Committees & 12 & 30 \\
\hline No of companies with females on the board & 12 & 30 \\
\hline Tenure on the board of directors & 11 & 28 \\
\hline $\begin{array}{l}\text { No of committees responsible for decision-making } \\
\text { on economic, environmental and social impacts }\end{array}$ & 12 & 28 \\
\hline $\begin{array}{l}\text { the frequency of the director board's review of } \\
\text { economic, environmental and social impacts, risks } \\
\text { and opportunities }\end{array}$ & 12 & 29 \\
\hline
\end{tabular}

\section{Discussion}

The main purpose of indicators is to provide information for decision-making regarding sustainability of companies' actions. Indicators also help to identify if the decision-makers have addressed the needs of multiple stakeholders that companies are responsible for. This study reported stakeholders as shareholders, employees and contractors, local communities, suppliers, government and regulators, industry, NGOs, education and research, media, civil society, customers and investment community. Comparable indicators also help those stakeholders in their decision-making whether they share same interest, different or conflicting interest. The companies in the sample mainly reported on indicators that were regulated, confirming the legitimacy theory. The pilot study which was conducted with companies in the top end of the sample were more compliant with the ESG reporting compared than when compared to the whole sample.

Analysis showed that regulatory compliance was a motivation for environmental and social reporting, for example 76.6\% the companies reported on Direct Green House Gas Emissions, whereas all the companies in the top end reported in the pilot study reported. Eighty three percent in the pilot study reported on injury rates and only $50 \%$ reported in whole sample, whereas compliance for corporate governance best practices were mainly the result of compliance with ASX Corporate Governance Principles and were reported by all the companies. Since the compliance with corporate governance code was a requirement for all companies listed on the ASX, all companies reported on the board structure. However, none of the companies reported on corruption, bribery, money laundering or fraud. This makes it unclear to the stakeholders, whether such activities were committed or if committed it has not been reported.

Most important issue for mining and mineral industries is the depletion of non-renewable resources, environmental impacts of air emissions, waste generation, disturbance to natural habitats resulting in loss of biodiversity (Azapagic 2004). This study also addressed the environmental reporting by mining companies related to non-renewable resources, GHG emissions, management of bio-diversity, ozone depleting substance, hazardous and non-hazardous waste, water usage and spills. However, except for direct GHG emissions, percentage of reporting was rather low.

Azapagic (2004) consider social issues from a micro and macro perspectives. Micro is referred to in the perspective of employees and macro concerns the society at large. Issues related to employees were the most reported in this study. Health and safety is an issue specific to mining industry. Accidents in the mining industry, poses above average risk to employees, resulting in high fatalities, were also reported by over fourty one percent of the companies in the sample. Mining employees are also exposed to health concerns related to hostile working environment, however companies did not report on such data. Therefore it can be presumed that in relation to employees too many companies follow an implicit rule of reporting the least, but required information only. For instance, as explained above, injury rates and employee number or percentage by gender were the most reported categories.

Training related to employee education and skills development is an important issue for many companies due to the need for attracting high quality employees because of the negative image for the mining industry, however training related information was only reported by thirty thirteen percent of 
companies. Many companies tend to mention that they implement such programs but hesitate to report those in details.

Gender disparity is an issue for mining industry, which is traditionally male dominated. This explains the limited disclosures on gender related information in this study to total number of employees, employee turnover and females in senior management. However, more than fifty percent of the sample has mentioned the diversity based on gender and all the companies reported on females in the director board, since diversity is a requirement to comply with corporate governance code for all companies listed on the ASX.

Protection of human rights is an issue that is considered important for mining companies. Therefore, training on human rights policies and reporting on various human rights issues is considered important. Only thirteen percent of the companies in this study considered training on Human Rights policies important as a result conducted training programs. Even though the other companies in the sample did not report facts and figures, they also have mentioned that they are conducting programs on training on Human Rights. Indigenous employment is related to diversity policies of the federal and state legislation covering workplace diversity and equal opportunity in Australia.

Social issues related to society at large were reported mainly on health and safety. Mining activities also posed health and safety risk for the local communities related to extraction activities or mineral products. Thirty three percent of the sample has recorded explicitly a number or a percentage of operations they have implemented with local community engagements, under the heading of society. However, some companies in the sample only declared whether they have such agreement or not.

In Australia corporate governance practices are based on ASX principles which are voluntary. However it is aimed to improve governance, accountability and transparency. ESG reporting is also influenced by global institutions such as GRI, UN Global Compact and the carbon Disclosure Project. Principle 3.1 of ASX corporate governance recognise the legal and ethical obligation of the company, however the recommended practices related to $\mathrm{E} \& \mathrm{~S}$ are treated with minimal consideration among the companies in the sample, which poses the question whether in reporting $\mathrm{E} \& \mathrm{~S}$ disclosures companies face difficulties related to measurement or related to cost benefits issues etc.

Results reported measurements used for indicators. Measures used for environmental and social indicators is an issue, because the same indicator was measured differently by companies even in the same industry, for example, GHG emissions were reported in Tonnes, Kilo Tonnes and Mega Tonnes; value of renewable and non-renewable material was reported in AUD or USD; water withdrawn was reported in Mega litres and Giga litres; training on human rights policies were reported in number of hours, percentages or as per employee. The above findings show that comparability even among the same sectors is difficult for the purpose of decision-making by investors and other stakeholders.

These findings suggest that extent of reporting is either driven by regulators or to gain a reputation for social responsibility for capital markets and media. Therefore it is questionable if all ESG information is being reported, especially related to negative impact.

This research shows that all the companies reported on non- financial reporting, however extent of reporting was different. The fact that majority had a sustainability report or an integrated report confirms that non-financial reports are in the increase and ESG issues are becoming important among various stakeholders of companies. 


\section{Conclusion}

Whilst majority of companies have a sustainability report, the trend for integrated reporting seems to be in the increase. Extent of ESG reporting varied but those of regulatory or compliance nature were the most reported ESG information as well as those influenced by other global institutions which promote good ESG practices and also investor driven. Examination of ESG information showed, the information that gives negative reactions of the stakeholders was either not mentioned or least mentioned in the reports with the purpose of providing an optimistic picture to the stakeholders.

To respond to challenges related to different sustainability issues and stakeholder concerns, it is important to be able to disclose information that can be comparable within the different industries and sectors. Reporting of disclosure of information are not meaningful unless they are comparable. Findings of this study show that there is no uniformity in the types of measures used in similar data. Chvatalov'a, Kocmanov'a et al. (2011) also report that "even though GRI served as an essential tool and a very useful means of improving the standardisation of company reporting, companies continue to have differing degrees of compliance with GRI and also may differ in their interpretation of the best means to apply the standards to their reporting". This study clearly shows the need for uniform measures for ESG indicators and to develop a framework that can be used to measure ESG indicators for mining sector companies in Australia.

\section{References}

Azapagic, A. (2004). "Developing a framework for sustainable development indicators for the mining and minerals industry." Journal of Cleaner Production 12(6): 639-662.

Azapagic, A. and S. Perdan (2000). "Indicators of Sustainable Development for Industry: A General Framework." Process Safety and Environmental Protection 78(4): 243-261.

Bassen, A. and M. Kovacs (2008). "Environmental, Social and Governance Key Performance Indicators from a Capital Market Perspective."

Zeitschrift fuer Wirtschafts- und Unternehmensethik 9(2): 182-192.

Blanc, D., A. Cozic, et al. (2013) Choosing Indicators to Measure the ESG Performance of Investment.

Bonime-Blanc, A. (2014) Integrating "ESG" issues into global risk, compliance \& integrity programmes. Ethical Corporation

Bonini, S., T. Koller, M.,, et al. (2009). "Valuing Social Responsibility Programs." McKinsey on Finance 32(Summer).

Chartered Accountants of Canada (2010). Environmental, Social and Governance (ESG) issues in Institutional Investor Decsion Making. Ontario, Canada, Chartered Accountants of Canada.

Chvatalov'a, Z., A. Kocmanov'a, et al. (2011). Corporate Sustainability Reporting and Measuring Corporate Performance. Environmental Software Syastems: Frameworks of eEnvironment. A.

J. T. Seneca. New York, Springer.

Corporate Knights (2010). Prioritizing GRI Indicators by mainstream investors for manstream investors.

Daniel, J. (2012). Sampling Essentials: Practical Guidelines for Making Sampling Choices United Kingdom, Sage Publications.

Deegan, C. (2002). "Introduction: The legitimising effect of Social and Environmental Disclosures A Theoretical Foundation." Accounting, Auditing \& Accountability Journal 15(3): 282-311.

Deegan, C. (2004). Financial Accounting Theory. NSW, McGraw-Hill Australia Pty Ltd.

Deegan, C. (2014). An Overview of legitimacy theory as applied within the social and environmental accounting literature. Sustainability Accounting and Accountability. J. Bebbington, J. Unerman and B. O'Dwyer, Routledge: 248-272.

Donaldson, T. and L. E. Preston (1995). "The stakeholder theory of the corporation: concepts, evidence and implications." Academy of Management Review 20(1): 65-91. 
Dowling, J. and J. Pfeffer (1975). "Organisational legitimacy: social values and organisational behaviour." Pacific Sociological Review(January): 122-136.

EFFAs (2009). KPIs for ESG: A Guideline for the integration of ESG into Financial Analysis and Corporate Valuation, European Federation of Financial Analysts Societies. Version 1.2.

Financial Times (2014). "Definition of ESG." Retrieved 28 August, 2014, from http://lexicon.ft.com/Term?term=ESG.

Galbreath, J. (2013). "ESG in Focus: The Australian Evidence." Journal of Business Ethics 118(3): 529-541.

Global Reporting Initiative (2013). G4 Sustainability Reporting Guidelines, Global Reporting Initiative.

Global Reporting Initiative (2013). G4 Sustainability Reporting Guidelines: Reporting Prnciples and Standard Disclosures. Amsterdam, Global Reporting Initiative.

Goldman Sachs (2008). GS Sustain. June: 52.

Gray, R., R. Kouhy, et al. (1995). "Corporate Social and environmental reporting: a review of the literature and a longtitudinal study of UK disclosures." Accounting, Auditing \& Accountability Journal 8(2): 47-77.

Gray, R., D. Owen, et al. (1996). Accounting and Accountability; Changes and Challenges in Corporate Social Environmental Reporting. Harlow, Prentice -Hall Europe

Hamann R. (2003). " Mining companies' role in sustainable development: the 'why' and 'how' of corporate social responsibility from a business perspective." Development South Africa 20(2): 237-254.

Hřebíček, J., J. Soukopová, et al. (2011). "Integration of Economic, Environmental, Social and Corporate Governance Performance and Reporting in Enterprises." ACTA UNIVERSITATIS AGRICULTURAE ET SILVICULTURAE MENDELIANAE BRUNENSIS 15(7): 157-166.

Jenkins, H. and N. Yakovleva (2006). "Corporate social responsibility in the mining industry: Exploring trends in social and environmental disclosure." Journal of Cleaner Production 14: 271-284.

Jenkins HM (2004). "Corporate social responsibility and the mining industry: conflicts and constructs." Corporate Social Responsibility and Environmental Management 11: 23-34.

John Evans, J. and D. Peiris (2010) The Relationship between Environmental Social Governance Factors and Stock Returns. Australian School of Business Research Paper

Lindblom, C. K. (1994). The implications of organisational legitimacy for corporate social performance and disclosure. Critical Perspectives on Accounting Conference. New York, NY.

Lundstrom, E. and C. Svensson (2014). Including ESG concerns in the portfolio selection proces. School of Engineering Sciences. Stockholm, Sweden, KTH Royal Institute of Technology. Degree Program in Industrial Engineering and Management.

Martirosyan, E. and T. Vashakmadze (2013). "Introducing Stakeholder-Based Frameworks for Postmerger Integration (PMI) Success." Journal of Modern Accounting and Auditing 9(10).

Matthews, M. R. (1993). Socially Responsibkle Accounting. UK, Chapman \& Hall.

Neu, D., H. Warsame, et al. (1998). "Managing Public Impressions: Environmental Disclosures in Annual Reports." Accounting, Organizations and Society 23(3): 265-282.

O’Dwyer, B., D. Owen, et al. (2011). "Seeking legitimacy for new assurance forms: The case of assurance on sustainability reporting." Accounting, Organizations and Society 36(1): 31-52.

Owen, D. (2007). Assurance Practice in Sustainability Reporting. In Sustainability Accounting and Accountability. J. Unerman, J. Bebbington and B. O’Dwyer. London and New York, Routledge.

Patten, D. M. (1992). "Intra-industry environmental disclosures in response to the Alaskan oil spill: A note on legitimacy theory." Accounting, Organizations and Society 17(5): 471-475.

Patten, D. M. (2005). "The Accuracy of Financial Report Projections of Future Environmental Capital Expen- ditures: A Research Note', Accounting." Organizations and Society 30(5): 457-468.

Thorne, D., M.,, O. C. Ferrell, et al. (2011). Business \& Society: Strategic Approach to Social Responsibility and Ethics. USA, South-Western Cenagage Learning.

Tilling, M. V. (2004). "Some thoughts on legitimacy theory in social and environmental accounting." Social and Environmental Accountability Journal 24(2): 3-7. 
Tilt, C. A. (1994). "The Influence of External Pressure Groups on Corporate Social Disclosure." Accounting, Auditing \& Accountability Journal 7(4): 47-72.

NEP FI and Mercer (2007). Demystifying Responsible Investment Performance: A review of key academic and broker research on ESG factors UNEP FI and Mercer.

UNEP FI and WBCSD (2010). Translating environmental, social and governance factors into sustainable business value: Key insights for companies and investors.

UNEPF Asset Management Working Group (2009). Fiduciary responsibility Legal and practical aspects of integrating environmental, social and governance issues into institutional investment, UNEP FI.

Vintro, C. and J. Comajuncosa (2010). "CORPORATE SOCIAL RESPONSIBILITY IN THE MINING INDUSTRY: CRITERIAAND INDICATORS." Dyna 77(161): 31-41.

Warhurst A. (2001). "Corporate citizenship and corporate social investment: drivers of tri-sector partnerships." Journal of Corporate Citizenship 1(1): 57-73.

Yen, A. (2004). Effects on investor judgments from expanded disclosures of non-financial intangibles information. Accounting. Austin, University of Texas. Doctor of Philosophy. 
